\title{
1 Anatomical diversification of a skeletal novelty in bat feet
}

2 Kathryn E. Stanchak ${ }^{1 *}$, Jessica H. Arbour ${ }^{1}$, Sharlene E. Santana ${ }^{1}$

$3{ }^{1}$ Department of Biology and Burke Museum of Natural History and Culture, University of

4 Washington, Seattle, Washington 98195, USA

5 *Correspondence to: Katie Stanchak, Department of Biology, University of Washington, Box

6 351800, Seattle, WA 98195. E-mail: stanchak@uw.edu

8 Running Title: Diversification of the bat calcar

Author Contributions: KES and SES conceived of the project. KES collected and analyzed

11 data. KES, JHA, and SES interpreted the data analysis and wrote the paper.

Acknowledgements: We thank the Division of Mammals at the Smithsonian National Museum

14 of Natural History, the Department of Mammalogy at the American Museum of Natural History,

15 the Mammal Collection at the Museum of Vertebrate Zoology, the Slater Museum of Natural

16 History, the Mammal Collection at the Field Museum of Natural History, the Herring Lab at the

17 University of Washington, and the Lubee Bat Conservancy for providing access to specimens. L.

18 Leiser-Miller collected many specimens in the Santana Lab collection. O. Okoloko helped with

19 CT scans. L. Zeman, E. Johnson, and members of the Herring Lab advised on histological

20 technique, and A.P. Summers provided use of the $\mu \mathrm{CT}$ scanner at Friday Harbor Laboratories.

21 The project benefited from discussion with participants of the 2015 and 2018 Annual Meetings

22 of the North American Society for Bat Research. A.A. Curtis, Z.A. Kaliszewska, R.M. Kelly,

23 and L. Leiser-Miller provided advice on several manuscript drafts. KES was funded by a 
24 National Science Foundation (NSF) Doctoral Dissertation Improvement Grant (\#1700845), a

25 Theodore Roosevelt Memorial Grant from the American Museum of Natural History, a Grant-in-

26 Aid of Research from the American Society of Mammalogists, the Iuvo Award from the

27 University of Washington Department of Biology, and funds from the Department of

28 Mammalogy at the Burke Museum of Natural History and Culture. SES and JHA were funded by

29 NSF Grant \#1557125.

30

31 Data Accessibility Statement: CT scans will be uploaded to Morphosource upon acceptance

32 and available at time of publication. Data sets will be provided as Supporting Information

33 associated with the publication.

34

35

36

37

38

39

40

41

42

43

44

45

46 


\section{Anatomical diversification of a skeletal novelty in bat feet}

\section{ABSTRACT}

Neomorphic, membrane-associated skeletal rods are found in disparate vertebrate

50 lineages, but their evolution is poorly understood. Here we show that one of these elements - the

51 calcar of bats (Chiroptera) — is a skeletal novelty that has anatomically diversified. Our

52 comparisons of evolutionary models of calcar length and corresponding disparity-through-time

53 analyses indicate that the calcar diversified early in the evolutionary history of Chiroptera, as

54 bats systematically radiated after evolving the capacity for flight. We find interspecific variation

55 in a variety of anatomical parameters of probable importance for calcar function, which suggests

56 that adaptive advantages provided by the calcar led to its anatomical diversification. In addition

57 to overall length, we find that the calcar varies among bats in its tissue composition, and a

58 synovial joint is present at the articulation between the calcar and the calcaneus ankle bone in

59 some species. This suggests the calcar has a kinematic functional role. Our results demonstrate

60 that novel skeletal additions can become integrated into vertebrate body plans and subsequently

61 evolve into a variety of forms, potentially impacting clade diversification by expanding the

62 available morphological space into which organisms can evolve.

64 Keywords: evolutionary novelty; neomorphism; Chiroptera; morphology; early burst 


\section{INTRODUCTION}

Enigmatic, neomorphic anatomical elements are scattered throughout the paleontological

72 and neontological records of vertebrate evolution (Hall 2015). Recent fossil discoveries have

73 raised interest in one specific type of novel skeletal structure: the "styliform" elements of

74 vertebrates that use membranes to glide or fly (Fig. 1). This group of skeletal elements comprises

75 the calcar of bats (Schutt and Simmons 1998), the styliform cartilages of gliding rodents and one

76 marsupial (Coster et al. 2015, Kawashima et al. 2017, Johnson-Murray 1987, Jackson 2012), the

77 pteroid of pterosaurs (Bennett 2007), and was recently expanded to include the styliform element

78 of Yi qi, a maniraptoran theropod dinosaur (Xu et al. 2015) and the calcar of Maiopatagium

79 furculiferum, a haramiyid mammaliaform (Meng et al. 2017). Since these skeletal rods are now

80 known from disparate tetrapod lineages, they seem less like evolutionary oddities than

81 consequential skeletal novelties characteristic of membranous body plans. The literature on most

82 of these structures is limited to osteological descriptions, so much is still unknown about their

83 function, origin, and diversification. The pterosaur pteroid has been the focus of several studies

84 and has generated debates on its anatomy and function (summarized in Witton 2013), but

85 although the Pterosauria comprises a taxonomically diverse clade in which to explore pteroid

86 variation, the lack of extant successors in the lineage restricts detailed anatomical and functional

87 studies. In contrast, another of these neomorphic styliform elements - the bat calcar-is

88 widespread across extant bats, making it an ideal model system for gaining a better

89 understanding of the evolution of membrane-bound skeletal rods, and more generally, the

90 evolution of neomorphic skeletal elements.

Bats (Chiroptera) are systematically, morphologically, and ecologically diverse

92 (Simmons 2005, Fenton and Simmons 2015, Kunz and Fenton 2005). The calcar articulates with 
93 the calcaneus bone in the bat ankle and extends into the membrane that spans between the two

94 hindlimbs (Vaughan 1970; Fig. 1). The calcar abruptly appears in the early bat fossil record

95 (Onychonycteris finneyi, Onychonycteridae, Green River Formation, WY, USA; 52.5 Ma;

96 Simmons et al. 2008) and, based on its ubiquity among extant bats, seems to have become fixed

97 as part of the bat wing structure. It is typically described as a bony or cartilaginous element,

98 although histological studies to date have confirmed only the presence of cartilaginous tissue

99 with varying levels of mineralization (Schutt and Simmons 1998, Adams and Thibault 1999,

100 Czech et al. 2008, Stanchak and Santana 2018). Because bats are morphologically diverse and

101 cartilage can be a precursor of bone, it has been hypothesized that the calcars of some bat species

102 might be composed of bony tissue (Adams and Thibault 1999).

103 The calcars of the Old World fruit bats (Pteropodidae) are known to be different from

104 those of the other bats. Pteropodid calcars are described as inserting on the tendon of the

105 gastrocnemius muscle rather than articulating with the calcaneus and are consequently

106 hypothesized not to be homologous to the calcars of other bats (Schutt and Simmons 1998,

107 Kobayashi 2017). In previous phylogenetic hypotheses, Pteropodidae was considered the sister

108 clade to all of the other bat families, which were collectively referred to as the

109 "microchiroptera." However, after the phylogeny of Chiroptera was revised using molecular

110 data, non-pteropodid bats were rendered paraphyletic (Teeling et al. 2005). As a consequence,

111 the hypothesis of a lack of homology between the pteropodid calcar and that of the "microbats"

112 became a less-parsimonious explanation than that of a homologous calcar across Chiroptera.

113 In all animal clades with styliform elements, including bats, the evolution of membrane-

114 bound limbs and a new locomotor mode (flight or gliding) allowed entry into new ecological

115 space: the aerosphere. The bat fossil record demonstrates early taxonomic diversification coupled 
with a rapid expansion of their geographic distribution (Smith et al. 2012). The earliest known

117 bats, onychonycterids, have been found on both the North American and Eurasian Eocene land

118 masses (Hand et al. 2015). By the end of the Eocene, bats are known from six continental

119 landmasses (Smith et al. 2012, Hand et al. 2015). Onychonycteris. finneyi, which possessed the

120 earliest known calcar, also had the most transitional bat postcranial skeleton found to-date, with

121 limb proportions between those of bats and non-volant mammals (Simmons et al. 2008). Based

122 on its presence in the oldest bat fossils, the calcar may be part of the suite of adaptations that

123 allowed bats to functionally and ecologically radiate into varied niches after their initial invasion

124 of the aerosphere. If so, we predict that (1) bat calcars will be morphologically diverse in trait

125 parameters that theoretically affect function, and (2) calcar morphological diversification will

126 reflect the rapid early diversification of Chiroptera, as suggested by the fossil record.

128 the radiation of bats to test the predictions outlined above. We integrate a variety of methods to

129 analyze calcar anatomy across a broad sample of bat species spanning diverse ecologies. First,

130 we examine the variation in length of the calcar across Chiroptera and test different models of

131 calcar evolution to reveal the macroevolutionary patterns and potential underlying processes that

132 characterize calcar diversification. Then, we more closely investigate the anatomical diversity of

133 the calcar with micro-Computed Tomography $(\mu \mathrm{CT})$ scans to assess its status as a novel skeletal

134 addition rather than another type of skeletal modification (e.g., a repeated tarsal element), and we

135 integrate data from both $\mu \mathrm{CT}$ scans and histological sections to test the hypothesis that the calcar

136 has histologically diversified. Finally, we combine gross dissections and diffusible iodine-based

137 contrast-enhanced $\mu \mathrm{CT}$ (diceCT; Gignac et al. 2016) for the visualization of soft tissue to re- 
138 evaluate the hypothesis that the pteropodid calcar is not homologous to the calcar of other bats.

139 Collectively, these studies rigorously assess the scope and scale of bat calcar evolution.

141 MATERIAL AND METHODS

142 Calcar Length Measurements and Macroevolutionary Analyses

143 The length of a rod or shaft is one parameter that determines its ability to resist bending

144 under an applied load (Hibbeler 2007). Bat calcars generally take a rod-shaped form, so

145 comparisons of calcar length are informative about the potential functional importance of the

146 calcar across bats. A single observer (KES) made caliper measurements of calcar, tibia, and

147 forearm (i.e., radius) lengths of 1-9 fluid-preserved specimens representing 226 species and all

148 recognized families within Chiroptera. In total, the sample included 1,396 specimens with an

149 average of 6 specimens per species. A list of museum specimens is provided as a spreadsheet in

150 the Supporting Information. By measuring intact, fluid-preserved specimens, we ensured that any

151 thin, cartilaginous portions of the calcar were present and measured. We rounded caliper

152 measurements to the nearest $1 \mathrm{~mm}$ to reflect imprecision in measuring skeletal features from

153 external examination of intact specimens. Because we based all measurements on external

154 examination of specimens, it is possible that a very small, not externally evident calcar resulted

155 in assigning a value of zero calcar length to some individuals (e.g., see Results regarding

156 Rhinopoma hardwickii). We did not include fossil bat species in our sample because few

157 postcrania are present in the bat fossil record and some extant calcars are unmineralized, so we

158 would not be able to confirm the absence of a calcar for any bat fossil species.

For each specimen, we calculated the ratio of the calcar length divided by either the tibia

160 or the forearm length and then averaged these ratios across all specimens for a particular species 
161 to derive a unitless measure of hindlimb skeletal proportions to compare across species. We

162 visualized the calcar-to-tibia length ratio character states on a pruned version of a relatively

163 recent chiropteran phylogeny (Shi and Rabosky 2015) using the "fastAnc" method of the

164 “contMap" function (Felsenstein 1985, Revell 2013) from the phytools v.0.6 package (Revell

165 2012) in R v.3.4.3 (R Core Team 2017; all analyses were performed in the same version of R).

166 We also calculated the residuals of phylogenetic generalized least squares regressions (pgls) of

167 mean calcar length on mean tibia or mean forearm length assuming a Brownian motion

168 correlation structure using the "phyl.resid" function (Revell 2009, Revell 2010) from the

169 phytools v.0.6 R package (Revell 2012). While the calcar-to-tibia length ratio is more intuitively

170 relevant to calcar biomechanics and function-even beyond its use for size normalization-we

171 used both the tibia and forearm ratios and pgls residuals in subsequent evolutionary analyses so

172 that we could better interpret the effect of variable transformations on our model fits. In addition,

173 we repeated all of the following analyses for datasets that did not include the species for which

174 we measured zero calcar length, and from which we excluded the Pteropodidae due to their

175 differing calcar anatomy. All data used in analyses are provided as a spreadsheet in the

176 Supporting Information.

177 To gain insight on the evolutionary processes that may have led to extant calcar diversity,

178 we fit three models of evolution (Brownian motion, early burst, and single-peak Ornstein-

179 Uhlenbeck) to the calcar length ratios and pgls residuals using the "fitContinuous" function in

180 the geiger v.2.0.6 R package (Harmon et al. 2007, Pennell et al. 2014). Brownian motion (BM)

181 models a "random-walk" process in which the variance of a trait increases linearly through time

182 (as defined in evolutionary modeling by the evolutionary rate parameter $\sigma^{2}$ ). It is often used to

183 test the hypothesis of trait evolution under a drift or other random process (Felsenstein 1973). 
184 The early burst (EB) model is used to test a niche-filling hypothesis consistent with an adaptive

185 radiation; the rate at which a trait diversifies decreases with declining ecological opportunity

186 after an initial, rapid "early burst" of diversification (Blomberg et al. 2003, Harmon et al. 2010).

187 The EB model is parameterized by the initial evolutionary rate $\left(\sigma^{2}\right)$ and a parameter for the

188 exponential change in evolutionary rates through time (a), such that when a $=0$ the EB model

189 reduces to the $\mathrm{BM}$ model and when $\mathrm{a}<0$ evolutionary rates decrease as time progresses. An

190 Ornstein-Uhlenbeck (OU) process is used to model an evolutionary process in which some

191 restoring force (e.g., selection; parameterized by $\alpha$ ) restrains a trait value $(\theta)$ through time

192 (Hansen 1997, Butler and King 2004). As implemented here, the model assumes a single optimal

193 trait value that is equal to the root ancestral state of the trait (parameterized by $\mathrm{z}_{0}$ in all models).

194 We compared these three models using small sample size-corrected Akaike weights ( $\left.w_{\text {AICc }}\right)$. If

195 the calcar underwent an early morphological diversification as the first bats systematically

196 radiated, we expected to find the highest support for the EB model.

To visualize and quantify the tempo of calcar length evolution, we performed a disparity-

198 through-time analysis using the "dtt" function (Harmon et al. 2003, Slater et al. 2010) from the

199 geiger v.2.0.6 R package (Harmon et al. 2007, Pennell et al. 2014) to calculate the mean

200 morphological disparity of each subtree in the pruned phylogeny using the average squared

201 Euclidean distance among all pairs of points. We plotted this curve against a null distribution

202 created by using the same procedure on a set of 1,000 simulations across the pruned phylogeny

203 assuming a BM model of evolution of the relative calcar lengths. We used the morphological

204 disparity index (MDI) to quantitatively compare subclade disparity in relative calcar length with

205 the disparity expected under a BM model (Harmon et al. 2003, Slater et al. 2010). We

206 determined the significance of the MDI by the frequency at which a calculated MDI between the 
207 data set and each simulation trial was greater than zero. A negative MDI value indicates that

208 disparity is partitioned more strongly among early divergence events, with more recent subclades

209 each representing only a small portion of the total morphological diversity of the clade than

210 expected under a constant-rate, random walk process (e.g., BM; Harmon et al. 2003, Slater et al.

211 2010). Positive MDI values may be indicative of selective constraint or increasing evolutionary

212 rates, where each recent subclade is more likely to represent a greater proportion of trait space

213 (López-Fernández et al. 2013). A negative MDI supports a hypothesis of early, rapid

214 morphological diversification prior to a period of relative stasis until the present day (Slater et al.

215 2010). To more rigorously assess the prediction of early disparification, we also performed

216 disparity-through-time analyses in which we compared the results from our data against

217 simulated results generated under an EB model of evolution (Slater and Pennell 2014).

$218 \quad$ CT Scanning

219 To examine calcar anatomy in the context of other ankle and foot bones across bat

220 species, we dissected and $\mu \mathrm{CT}$ scanned one foot of each of 19 fluid-preserved bat specimens

221 representing 13 families within Chiroptera. We also $\mu \mathrm{CT}$ scanned three whole (non-dissected)

222 fluid-preserved specimens representing three additional bat families (Appendix S1) for a total

223 sample of 22 species representing 16 families. These specimens were sourced from museum

224 collections, research collections in the Santana Lab and the Herring Lab at the University of

225 Washington, and the Lubee Bat Conservancy. We segmented (digitally-dissected) the tarsals, the

226 calcar, and other accessory ossicles in each $\mu \mathrm{CT}$ scan using Mimics v.19 (Materialise). The

227 resulting 3D renderings allowed us to compare tarsal osteology across our samples in

228 unprecedented detail. 
Previous studies of pteropodid calcar anatomy describe a calcar that inserts on the tendon

230 of the gastrocnemius muscle. This tendon then inserts on the calcaneal tuberosity. In contrast,

231 calcars of the paraphyletic "microbats" articulate directly with the calcaneus. To better assess the

232 soft tissue morphology of the calcars in Pteropodidae, we used diffusible-iodine contrast-

233 enhanced $\mu \mathrm{CT}$ scanning (diceCT, Gignac et al. 2016) and conventional $\mu \mathrm{CT}$ scanning to image

234 the feet of the three pteropodid species in our sample. For diceCT scanning, we placed each

235 fluid-preserved specimen in a solution of Lugol's iodine (3\% total solute) for two to three days

236 prior to CT scanning. The iodine solution increases the x-ray opacity of soft tissue-particularly

237 muscle - in the sample, allowing for the visualization of this tissue in the $\mu$ CT scan. Then, we

238 dissected each of the pteropodid feet to further assess the connection between the calcar spur and

239 the calcaneus ankle bone. A list of scanned specimens and $\mu \mathrm{CT}$ scanner settings is provided in

240 Appendix S1.

$241 \quad$ Histology

242 We used both the $\mu \mathrm{CT}$ scans and histological sections of the dissected specimens to

243 compare calcar tissue composition across 18 bat species (Appendix S1). Calcified calcar samples

244 were first decalcified in 14\% EDTA aqueous solution neutralized with ammonium hydroxide.

245 Because we had difficultly completely decalcifying some samples in EDTA, we transferred them

246 to 5\% aqueous formic acid for further decalcification. We then dehydrated, cleared, and

247 embedded all samples in paraffin wax. We sectioned each paraffin block at 5-8 micrometers with

248 a Leica RM2145 microtome, mounted the sections to slides, then cleared, rehydrated, and stained

249 the sections using either modified Mayer's hematoxylin and Mallory's triple connective tissue

250 stain (Humason 1962) or Weigert's iron hematoxylin and fast green/safranin O. For all samples,

251 we determined calcar tissue composition by cell and substrate morphology, not by stain color. 
252 We imaged the sections with a Nikon Eclipse E600FN compound microscope and an AmScope

253 MU300 camera.

254

\section{RESULTS}

256 The calcar exhibits extensive anatomical diversity across Chiroptera. Calcars range from

257 not externally visible (a length of zero) to considerably longer than the tibia (Fig. 2). We found

258 strong support $\left(w_{\mathrm{AICC}}>0.99\right)$ for the $\mathrm{EB}$ model of morphological evolution for calcar length

259 relative to tibia length in all model comparisons that included pteropodid bats in the sample

260 (Table 1). All OU models collapsed to BM models, so only model results for BM and EB models

261 are shown. Support for the EB model decreased for the sample that did not include Pteropodidae.

262 Disparity-through-time analyses supported early diversification of calcar length in all cases, as

263 evidenced by significantly low MDI values when compared to a null BM distribution (Fig. 2,

264 Table 2). MDI values consistently increased when the calcar length disparity-through-time curve 265 was compared to a distribution generated under an EB model of evolution.

267 numerous tarsal modifications and collectively contain multiple accessory ossicles (Fig. 3;

268 descriptions in Appendix S1). However, none of these osteological modifications refute the 269 status of the calcar as a skeletal neomorphism or morphological novelty. In no bat species is the

270 calcar contiguous with another tarsal, nor is the calcar an obviously repeated skeletal element.

271 The calcar of any one bat species is only anatomically similar in both structure and location to

272 calcars of other bats and not to another tarsal element.

273 Histological sections complemented the $\mu \mathrm{CT}$ scans in revealing tissue-level diversity in

274 bat calcars. While calcars are predominantly composed of uncalcified or calcified cartilage, some 
275 calcars contain ossified tissue (Fig. 4; Appendix S1). The calcar of Noctilio leporinus

276 (Noctilionidae) is composed of thick cortical bone in the section proximal to the ankle, and both

$277 \mu \mathrm{CT}$ scans and histological sections demonstrated the formation of trabeculae (Fig. 4a, b, c). The

278 type of connective tissue also varies within a single calcar, along a continuum of cartilage,

279 calcified cartilage, and bone. The calcar of Molossus molossus (Molossidae) is bony proximately

280 and cartilaginous distally; as the bone grades into cartilage, only the interior of the calcar shaft is

281 bony, and this bony tissue is surrounded by a thick layer of tissue that appears more cartilage-

282 like (Fig. 4d, e). This partially bony calcar contrasts with the typical cartilaginous calcar of the

283 other species, as exemplified by the primarily calcified cartilage calcar of Eptesicus fuscus (Fig.

284 4f). Both the E. fuscus and M. molossus calcars are surrounded by a thick, perichondrium-like

285 envelope (Fig. 4e and 4f, respectively). Pteronotus quadridens (Mormoopidae) and Macrotus

286 waterhousii (Phyllostomidae) also have bony proximal ends of their calcars, but the degree to

287 which this ossification extends distally varies between the two species (Appendix S1). The short

288 calcar of Desmodus rotundus (Phyllostomidae) also exhibits bony tissue (Fig. 4g).

289 Histological sections also confirmed the presence of a synovial joint between the calcar

290 and the calcaneus in several bat species (Fig. 4e, f, g; Appendix S1) and the presence of a

291 relatively small, uncalcified, cartilaginous calcar in one species in which the calcar was thought

292 to be absent (Rhinopoma hardwickii, Rhinopomatidae; Fig. 4h). Our anatomical analyses also

293 highlighted known shape differences across bat calcars; although most calcars take the form of a

294 rod with an approximately elliptical cross-section, some exhibit notably divergent shapes. For

295 example, a cartilaginous hook-like "keel" structure protrudes from the main shaft of the calcar in

296 some species, including Eptesicus fuscus, Myotis californicus (both Vespertilioonidae), and

297 Thyroptera tricolor (Thyropteridae). The bony portion of the calcar of Noctilio leporinus 
298 exhibits an antero-posteriorly flattened cross-section with multiple cavities in the bony tissue

299 (Fig. 4b). We describe, for the first time, that the calcar of Mystacina tuberculata (Mystacinidae)

300 has two distinct calcified tines (Fig. 3e, f), a unique morphology among the calcars in our

301 sample.

The diceCT scans and dissections of pteropodid feet revealed calcar anatomical diversity

303 within the Pteropodidae. The diceCT scan of Cynopterus brachyotis indicates that the calcar and

304 the tendon of the gastrocnemius muscle make two separate, distinct insertions on the calcaneal

305 tuberosity. We confirmed this observation through a dissection in which we were able to cleanly

306 pass a pin between the insertions of the calcar and the tendon on the calcaneus (Fig. 5). However,

307 dissections of the calcars of Rousettus aegyptiacus and Pteropus sp. indicated that the calcar

308 tissue is contiguous with the tendon of the gastrocnemius muscle. DiceCT scans of these species

309 were inconclusive, as iodine solution only slightly increases CT scan image contrast in cartilage.

310 More detailed anatomical descriptions of each species examined with $\mu \mathrm{CT}$ scanning and

311 histological sectioning are provided in Appendix S1.

\section{DISCUSSION}

The bat calcar is a skeletal novelty that has anatomically diversified widely throughout

315 Chiroptera. This diversification appears to have occurred early in chiropteran history, as

316 evidenced by support for an early burst model of calcar length evolution and the corresponding

317 negative morphological disparity indices. This is consistent with evidence for early

318 diversification of bats in the fossil record and an overall declining rate of speciation in

319 Chiroptera (Shi and Rabosky 2015). Eocene bat postcrania are best preserved in the Green River

320 Formation and the famous Messel Lagerstätten near Messel, Germany. Although Onychonycteris 
321 finneyi is known to have had a calcar, no calcars have been found in postcranial fossils of

322 Icaronycteris index, a later Green River bat with limb proportions typical of some extant bats.

323 Among the Messel bats, Hassianycteris, Palaeochiropteryx, and Tachypteron had calcars, but no

324 calcars have been reported in specimens of Archaeonycteris (Simmons and Geisler 1998, Storch

325 et al. 2002). Additionally, no evidence of an articulation facet has been found on the calcanei of

326 Icaronycteris and Archaeonycteris (Simmons and Geisler 1998). Because calcars vary in amount

327 of calcification, it is possible that uncalcified cartilage calcars were not preserved in these taxa;

328 nonetheless, it is clear that Eocene bats exhibited diversity in either the presence of a calcar or in

329 the amount of calcar calcification soon after the first bats evolved flight.

We found weaker support for the EB model when only non-pteropodid calcars were

331 included in the analyses. However, our pteropodid diceCT scan and dissection results call into

332 question the proposition that the pteropodid calcar is not homologous to the calcar of other bats.

333 We have demonstrated that the calcar morphology of at least one pteropodid individual

334 (Cynopterus brachyotis) differs from the calcar morphology of other pteropodids; its relation to

335 the surrounding connective tissue makes it more similar to the "microbat" calcar condition. This

336 intermediate anatomical condition in C. brachyotis suggests that it is more appropriate to

337 consider the calcars of all bats in macroevolutionary analyses, rather than just those of the

338 paraphyletic "microchiroptera."

340 macroevolution literature (Harmon et al. 2010). It has been proposed that this could be an

341 artefact of either hypothesis testing at too low of a taxonomic level, such that the signal of the

342 "early burst" of the higher-level clade has been lost, or a consequence of testing variables that

343 are not functionally-linked to the specific radiation, such as body mass and overall shape (Slater 
and Friscia, 2018). The evolution of wings in the early Chiroptera is a type of extensive morphological change that would be expected to precede a burst of diversification, as flight would allow access to an entirely new ecospace (other examples summarized in Erwin 2015).

347 The calcar abruptly appeared in the fossil record as part of this wing structure and is now found 348 in the vast majority of bats. When we tested an early burst hypothesis of calcar evolution across 349 all of Chiroptera, we found that the calcar - a distinct synapomorphy associated with an aerial ecological mode - retains the signal of an early diversification burst. The true key innovation,

351 however, is likely the full wing apparatus, which not only includes the novel calcar but also the 352 elongation of the forelimb bones and the evolution of novel and developmentally-retained wing

353 membranes. The functional relevance of the calcar within the wing is untested, although it is

354 generally assumed that the calcar plays a role in supporting the hindlimb membrane during flight 355 (Vaughan 1970).

Across extant bats, the calcar exhibits interspecific diversity in anatomical parameters

357 that are likely to affect function, both in terms of overall structure (e.g., length and shape) and 358 material (histological) composition. Although others have noted differences in the amount of 359 calcar calcification among species based on dissection observations and clearing and staining 360 procedures (Schutt and Simmons 1998, Koyabu and Son 2014, Reyes-Amaya et al. 2017), this is 361 the first study to confirm the presence of ossified tissue in the bat calcar. Given that there is 362 extensive variation in material properties between cartilage, calcified cartilage, and bone (Currey 363 2002), interspecific variation in calcar tissue composition, length, and/or shape would result in 364 interspecific differences in responses to applied loading (e.g., muscular contraction or resistance 365 of a stretched membrane). Bat hindlimbs play important functional roles in prey capture (Fish et 366 al. 1991), roosting (Simmons and Quinn 1994), and possibly flight (Cheney et al. 2014). The 
anatomical variation described here suggests calcar function may vary across species with different ecologies that are subject to different functional evolutionary pressures. For instance, in Myotis, long calcars were found to be associated with a trawling foraging strategy (Fenton and Bogdanowicz 2002). Additionally, the presence of a synovial joint between the calcar and the

371 calcaneus, in combination with the presence of skeletal muscles that insert on the calcar (Schutt

372 and Simmons 1999, Glass and Gannon 1994, Stanchak and Santana 2018), suggests a kinematic

373 functional role for the calcar. Although there are reported observations of moving calcars (e.g., in

374 Noctilio leporinus as they trawl bodies of water for fish prey; Vaughan 1970, Altenbach 1989),

375 calcar motion has not yet been confirmed with a rigorous kinematic analysis in any bat species.

376 Further detailed, quantitative analyses of calcar biomechanics, including material testing and

377 behavioral experiments, are required to estimate the magnitude of the effect of anatomical 378 variation on any potential calcar function. which "seem to appear out of nowhere, de novo, but are present in most if not all individuals of a

381 species" as well as Müller and Wagner's (1999) definition of a morphological novelty as “neither

382 homologous to any structure in the species nor homonomous to any other structure of the same

383 organism." Although the immediate ancestry of the chiropteran lineage is unknown (Halliday et

384 al. 2017), no calcar-like structure is found in earlier eutherian mammals. However, the discovery

385 of a calcar in a Mesozoic mammaliaform (Meng et al. 2017) raises the possibility of a deep

386 homological explanation for the origin of calcar (Shubin et al. 2009). 
incremental support for this hypothesis. Connective tissue (cartilage, tendon, and even bone) is

391 both plastic and labile (Hall 2015). The calcar may have arisen in a mass of connective tissue in

392 close proximity to the calcaneus, perhaps as that mass of tissue was placed under stress during

393 the development of the hindlimb membrane. Consequently, differences among species in the

394 association of the calcar with the calcaneus may be the result of relatively minor developmental

395 alterations. Our finding of many sesamoids in bat feet, consistent with a recent assessment of bat

396 sesamoids (Amador et al. 2018), suggests a propensity for metaplastic cartilage and bone

397 development in bat feet, as tendon metaplasia is hypothesized to play a role in sesamoid

398 development (Sarin et al. 2002; but see also Eyal et al. 2015, 2018). Developmental plasticity

399 may also lead to intraspecific variation in calcar anatomy or even presence. This might be a

400 fruitful path of further study in light of our finding of a small, calcar-like structure in the foot of

401 one specimen of Rhinopoma hardwickii.

Anatomical structures of ambiguous homology are under-explored in studies of morphological evolution. The bat calcar is an anatomically diverse skeletal novelty found in a

404 vast majority of species of a highly diverse clade of vertebrates. It evolved into a potentially

405 functionally-important part of the bat wing, morphologically diversifying during the early

406 radiation of bats. Additional, focused studies of the bat calcar-especially of its function and

407 development - have a high potential to yield new knowledge of skeletal biology and a better

408 understanding of the mechanisms through which the skeleton evolves into novel forms. 


\section{TABLES}

414 Table 1. Results from evolutionary model comparisons. Calcar/Tibia and Calcar/Forearm

415 indicate models considering ratios of calcar length to tibia and forearm length, respectively;

416 Calcar Tibia and Calcar Forearm indicate models using residuals of phylogenetic regressions of

417 the same variables. $\mathrm{BM}=$ Brownian motion model; $\mathrm{EB}=$ Early Burst model; $\mathrm{a}, \sigma^{2}$, and $\mathrm{z0}$ are the

418 fit parameters of those models corresponding to the names used in the "fitContinuous" function

419 (see Material and Methods); $w_{\mathrm{AICc}}=\mathrm{AIC}_{\mathrm{c}}$ weights. All OU models collapsed to BM models, so

420 only BM and EB results are shown. Bold text emphasizes models with $w_{\mathrm{AICc}}>0.99$. 


\begin{tabular}{|c|c|c|c|c|c|c|}
\hline & Model & $\sigma^{2}$ & $\mathrm{z0}$ & $\mathrm{a}$ & $w_{\mathrm{AICc}}$ & $\Delta \mathrm{AIC}_{\mathrm{c}}$ \\
\hline \multicolumn{7}{|l|}{ Calcar/Tibia } \\
\hline \multirow[t]{2}{*}{ all data } & $\mathrm{BM}$ & 0.0011 & 0.7073 & -- & $<0.001$ & 23.579 \\
\hline & EB & 0.0056 & 0.6872 & -0.0434 & $>0.999$ & $\mathbf{0}$ \\
\hline \multirow[t]{2}{*}{ no zero lengths } & $\mathrm{BM}$ & 0.0010 & 0.7568 & -- & $<0.001$ & 16.167 \\
\hline & EB & 0.0041 & 0.7524 & -0.0374 & $>0.999$ & $\mathbf{0}$ \\
\hline \multirow[t]{2}{*}{ no zero lengths or Pteropodidae } & $\mathrm{BM}$ & 0.0010 & 0.8348 & -- & 0.0477 & 5.952 \\
\hline & EB & 0.0034 & 0.8313 & -0.0299 & 0.9353 & 0 \\
\hline \multicolumn{7}{|l|}{ Calcar/Forearm } \\
\hline \multirow[t]{2}{*}{ all data } & $\mathrm{BM}$ & 0.0002 & 0.2854 & -- & $<0.001$ & 22.207 \\
\hline & EB & 0.0008 & 0.2787 & -0.0416 & $>0.999$ & $\mathbf{0}$ \\
\hline \multirow[t]{2}{*}{ no zero lengths } & $\mathrm{BM}$ & 0.0001 & 0.3055 & -- & 0.0009 & 13.962 \\
\hline & EB & 0.0005 & 0.3053 & -0.0345 & 0.9987 & $\mathbf{0}$ \\
\hline \multirow[t]{2}{*}{ no zero lengths or Pteropodidae } & BM & 0.0002 & 0.3373 & -- & 0.1415 & 3.485 \\
\hline & EB & 0.0004 & 0.3374 & -0.0252 & 0.8081 & 0 \\
\hline \multicolumn{7}{|l|}{ Calcar $\sim$ Tibia } \\
\hline \multirow[t]{2}{*}{ all data } & $\mathrm{BM}$ & 0.4344 & 0.0 & -- & $<0.001$ & 20.036 \\
\hline & EB & 2.1063 & -0.3221 & -0.0412 & $>0.999$ & $\mathbf{0}$ \\
\hline \multirow[t]{2}{*}{ no zero lengths } & BM & 0.3899 & 0.0 & -- & 0.0007 & 14.395 \\
\hline & EB & 1.6065 & -0.0694 & -0.0365 & 0.9990 & $\mathbf{0}$ \\
\hline \multirow[t]{2}{*}{ no zero lengths or Pteropodidae } & $\mathrm{BM}$ & 0.3491 & 0.0 & -- & 0.1577 & 3.212 \\
\hline & EB & 0.8923 & -0.0675 & -0.0234 & 0.7861 & 0 \\
\hline \multicolumn{7}{|l|}{ Calcar $\sim$ Forearm } \\
\hline \multirow[t]{2}{*}{ all data } & $\mathrm{BM}$ & 0.4489 & 0.0 & -- & $<0.001$ & 16.869 \\
\hline & EB & 1.9658 & -0.2503 & -0.0383 & $>0.999$ & $\mathbf{0}$ \\
\hline \multirow[t]{2}{*}{ no zero lengths } & $\mathrm{BM}$ & 0.4092 & 0.0 & -- & 0.0038 & 11.149 \\
\hline & EB & 1.4769 & -0.0112 & -0.0328 & 0.9949 & $\mathbf{0}$ \\
\hline \multirow[t]{2}{*}{ no zero lengths or Pteropodidae } & $\mathrm{BM}$ & 0.3763 & 0.0 & -- & 0.3999 & 0.270 \\
\hline & EB & 0.7381 & 0.0004 & -0.0165 & 0.4577 & 0 \\
\hline
\end{tabular}


438 Table 2. Results from disparity-through-time analyses. MDI = morphological disparity index;

$439 \mathrm{BM}=$ Brownian motion model; $\mathrm{EB}=$ Early Burst model.
$\operatorname{MDI}(\mathrm{BM})$
MDI (EB)

\begin{tabular}{lll}
\hline Calcar/Tibia & $-0.284(\mathrm{p}<0.001)$ & $-0.105(\mathrm{p}=0.034)$ \\
all data & $-0.275(\mathrm{p}<0.001)$ & $-0.119(\mathrm{p}=0.036)$ \\
no zero lengths & $-0.236(\mathrm{p}=0.002)$ & $-0.112(\mathrm{p}=0.063)$ \\
no zero lengths or Pteropodidae & & $-0.113(\mathrm{p}=0.023)$ \\
\hline Calcar/Forearm & $-0.287(\mathrm{p}<0.001)$ & $-0.125(\mathrm{p}=0.013)$ \\
all data & $-0.278(\mathrm{p}<0.001)$ & $-0.113(\mathrm{p}=0.065)$ \\
no zero lengths & $-0.223(\mathrm{p}=0.001)$ & $-0.056(\mathrm{p}=0.182)$ \\
no zero lengths or Pteropodidae & $-0.066(\mathrm{p}=0.161)$ \\
\hline Calcar $\sim$ Tibia & $-0.223(\mathrm{p}<0.001)$ & $-0.0898(\mathrm{p}=0.108)$ \\
all data & $-0.221(\mathrm{p}=0.001)$ & \\
no zero lengths & $-0.195(\mathrm{p}=0.003)$ & $-0.055(\mathrm{p}=0.195)$ \\
no zero lengths or Pteropodidae & $-0.0752(\mathrm{p}=0.128)$ \\
\hline Calcar $\sim$ Forearm & $-0.222(\mathrm{p}=0.001)$ & $-0.0931(\mathrm{p}=0.129)$ \\
all data & $-0.207(\mathrm{p}=0.004)$ & \\
no zero lengths & $-0.17(\mathrm{p}=0.027)$ & \\
no zero lengths or Pteropodidae & & \\
\hline
\end{tabular}




\section{FIGURES}

450 Figure 1. Neomorphic skeletal rods have evolved multiple times in vertebrates with gliding or

451 flying membranes. These structures are indicated in pink in the schematic drawing. Drawings

452 based on Xu et al. 2015, Meng et al. 2017, Bennett 2007, Witton 2013, Coster et al. 2015,

453 Kawashima et al. 2017, Johnson-Murray 1987, Jackson 2012. 
bioRxiv preprint doi: https://doi.org/10.1101/490854; this version posted December 22, 2018. The copyright holder for this preprint (which was not certified by peer review) is the author/funder, who has granted bioRxiv a license to display the preprint in perpetuity. It is made available under aCC-BY-NC-ND 4.0 International license.

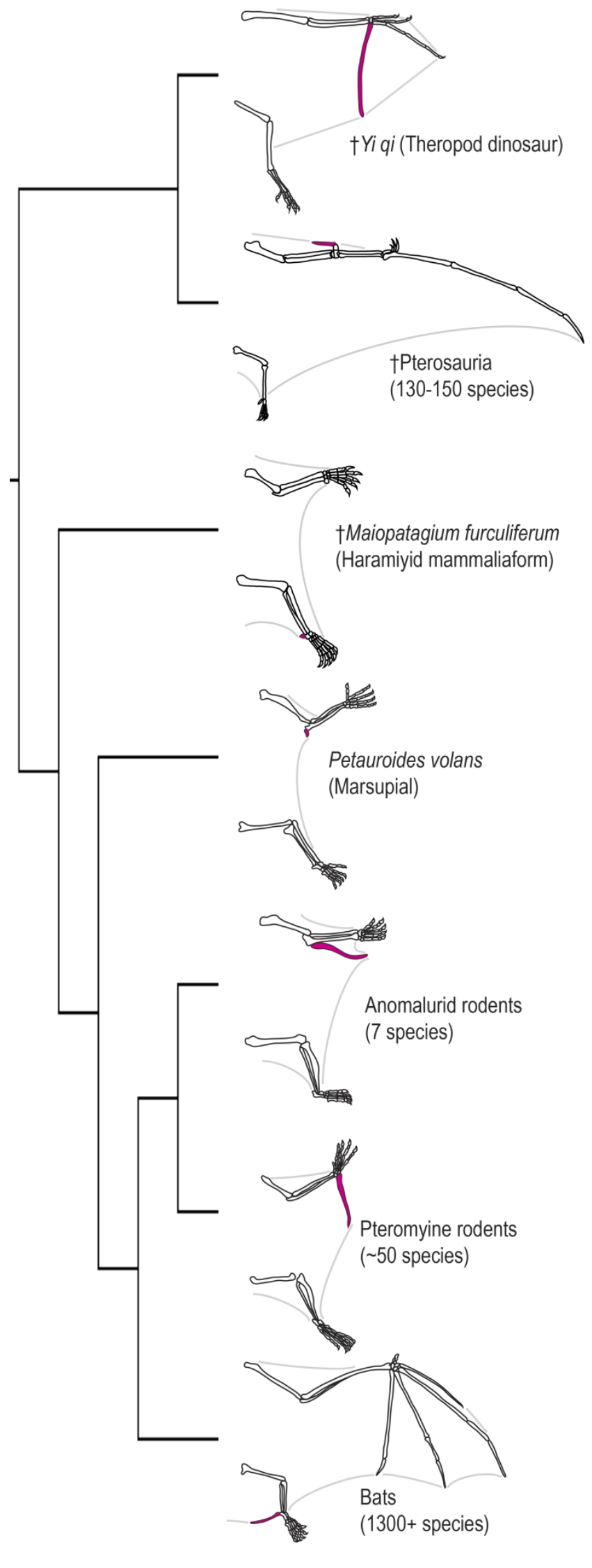


455 Figure 2. Relative calcar length varies extensively and diversified early in bat evolutionary

456 history. Ratio of calcar length-to-tibia length is plotted on a phylogeny of Chiroptera. Gray lines

457 around the phylogenetic tree designate bat families; species-rich families are labeled. Schematic

458 drawing on the color scale illustrate representative hindlimb morphologies for different calcar

459 lengths. In the diversity-through-time plot of mean subclade disparity, the black line indicates the

460 mean subclade disparity through time for the measured calcar-to-tibia length ratios, the dotted

461 line to 1,000 Brownian motion simulations, and the gray band a 95\% confidence range for the

462 simulations.
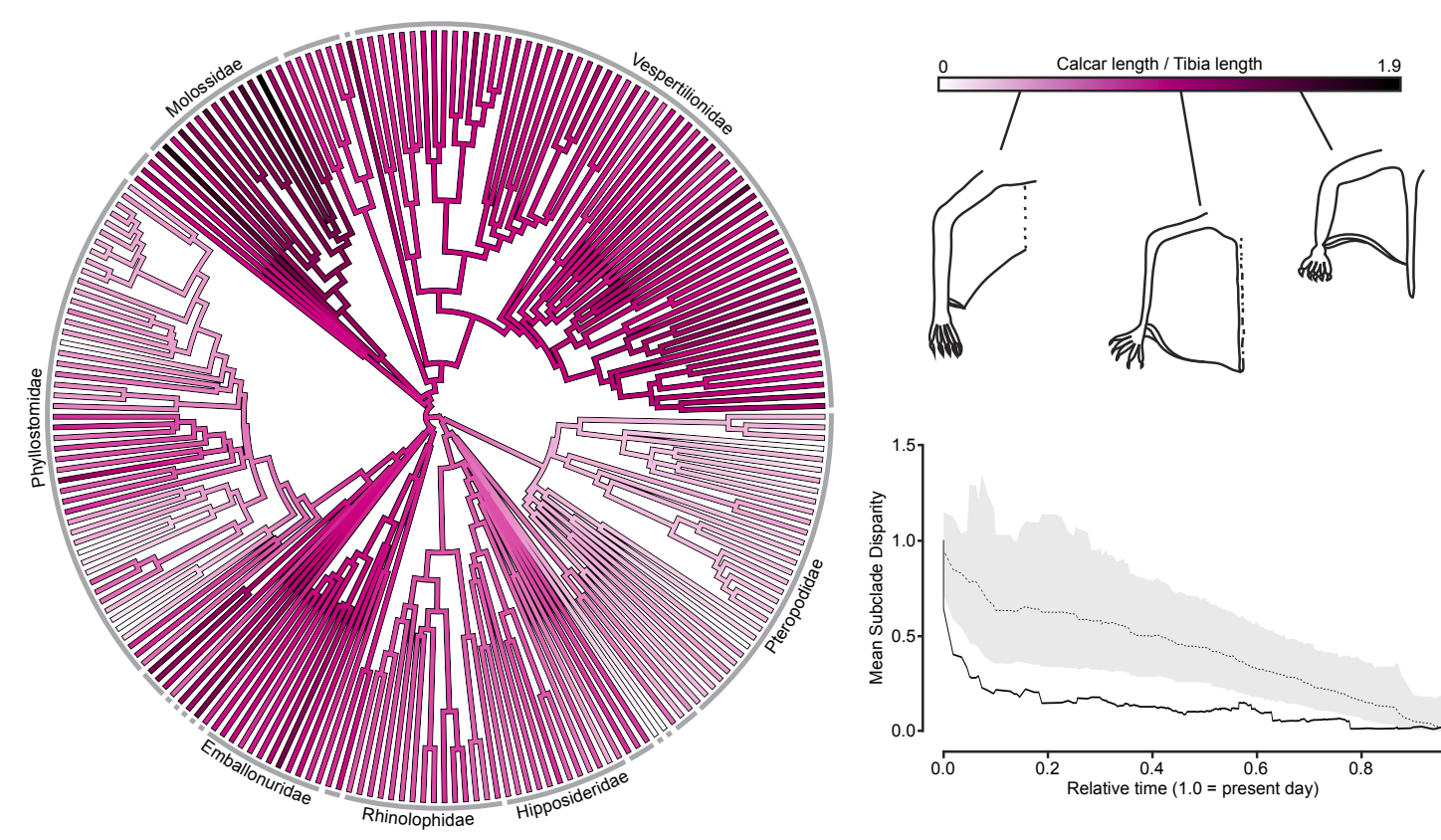
468 Figure 3. Bat ankle morphologies as demonstrated by rendered $\mu \mathrm{CT}$ scans. (a) Ankle of

469 Balantiopteryx plicata, demonstrating calcar-calcaneus articulation (in pink-yellow), the other

470 typical mammalian tarsals (in addition to the calcaneus; in shades of gray), and an additional

471 sesamoid (in green). Inset demonstrates the ankle position relative to the full leg. Other bat feet

$472 \mu \mathrm{CT}$ scans pictured are (b) Noctilio leporinus, (c) Desmodus rotundus, (d) Rhinolophus affinis

473 (AMNH 234034; calcar not visible due to lack of calcification), (e and f) Mystacina tuberculata

474 (MVZ 173918). All are pictured in plantar view except (f), which is medial to show calcified

475 tines on calcar.

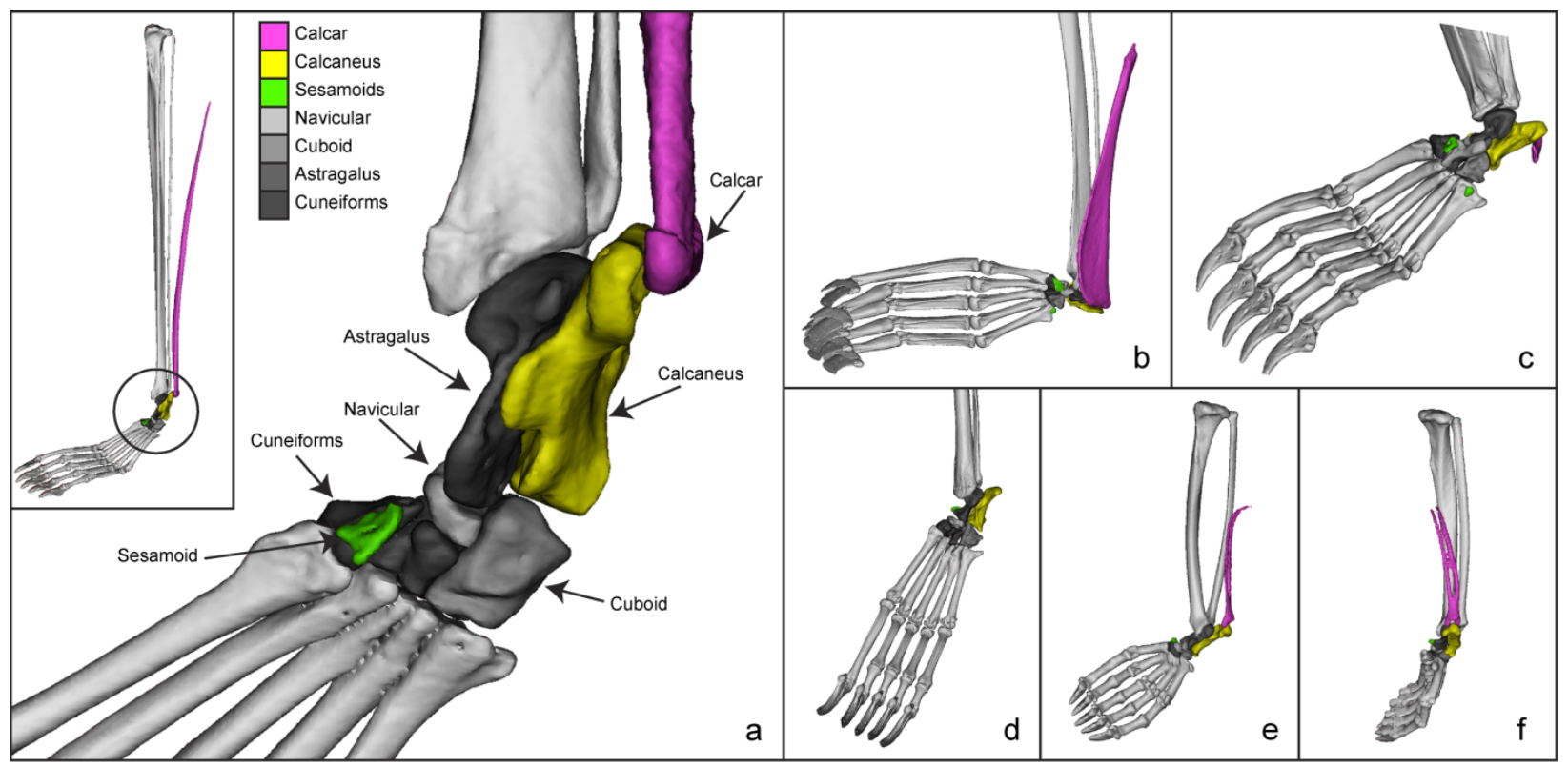


484 Figure 4. Histological diversity in the bat calcar. (a) Slice of $\mu \mathrm{CT}$ scan through the longitudinal

485 axis of the calcar of Noctilio leporinus. (b) Axial $\mu \mathrm{CT}$ scan slice through the hindlimb of $N$.

486 leporinus, demonstrating cross-sectional shapes of the calcar and leg bones. (c) Mallory-stained

487 histological section through the ankle of $N$. leporinus, demonstrating bony calcar tissue and a

488 ligamentous connection between the calcar and calcaneus. (d) Slice of $\mu \mathrm{CT}$ scan and (e) fast

489 green/safranin O-stained histological section through the longitudinal axis of the calcar of

490 Molossus molossus, demonstrating bony tissue in the calcar near the synovial joint with the

491 calcaneus, which then transitions distally to calcified cartilage. (f) Fast green/safranin O-stained

492 histological section of Eptesicus fuscus, showing a fully-cartilaginous calcar and a synovial joint

493 between the calcaneus and the calcar. (g) Mallory-stained histological section of Desmodus

494 rotundus, demonstrating bony nodule of calcar near the synovial articulation with the calcaneus.

495 (h) Mallory-stained histological section demonstrating calcar presence in Rhinopoma hardwickii

$496(\mathrm{FMNH} 123185) . \mathrm{Ca}=$ calcar, $\mathrm{Cs}=$ calcaneus, $\mathrm{Fi}=$ fibula, $\mathrm{Ti}=$ tibia. $\mathrm{In}$ all sections the scale bar 497 indicates $100 \mu \mathrm{m}$, except for (b) and (b) where it is $500 \mu \mathrm{m}$. 
bioRxiv preprint doi: https://doi.org/10.1101/490854; this version posted December 22, 2018. The copyright holder for this preprint (which was not certified by peer review) is the author/funder, who has granted bioRxiv a license to display the preprint in perpetuity. It is made available under aCC-BY-NC-ND 4.0 International license.

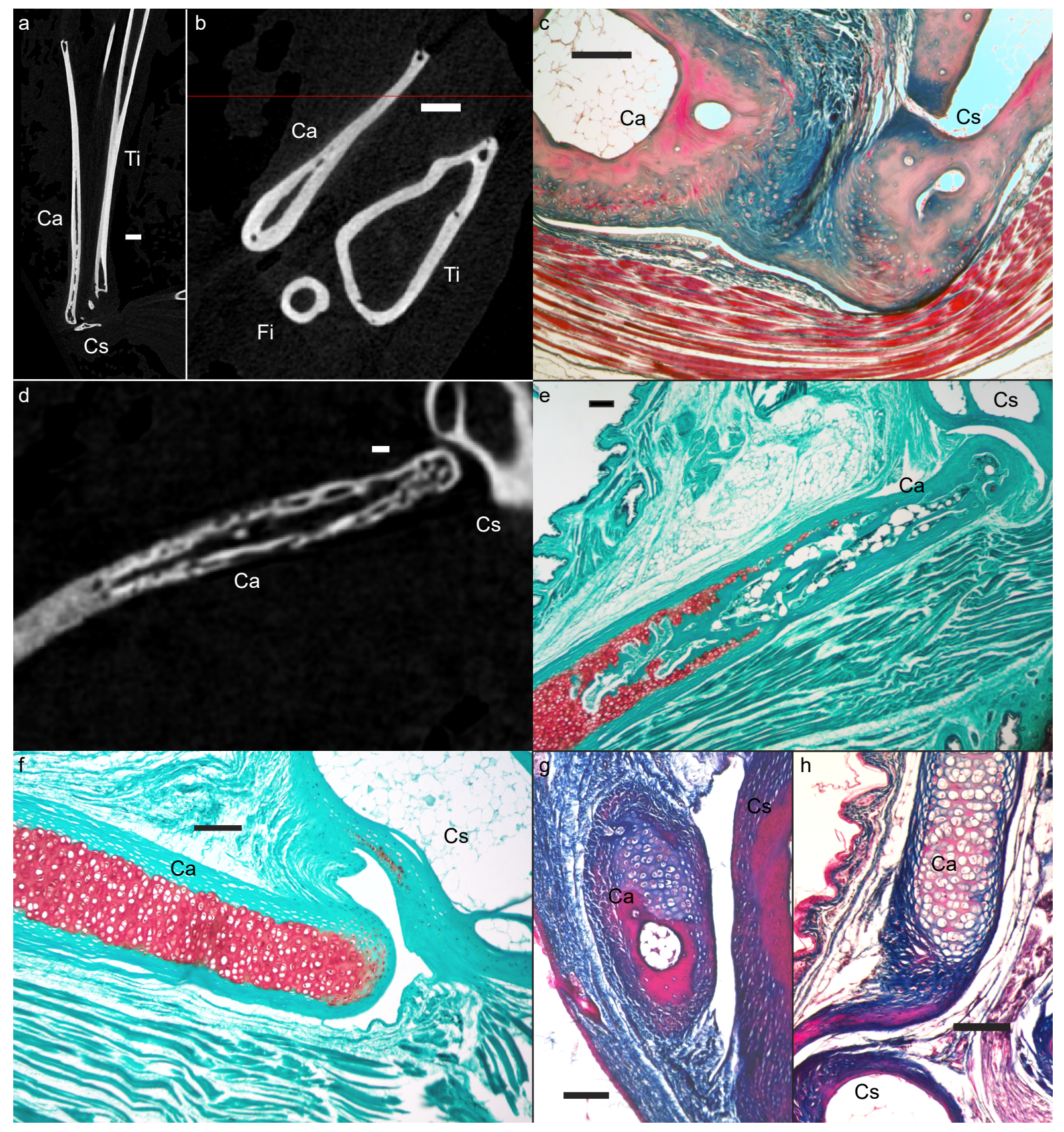


500 Figure 5. Photographs of dissection of the Cynopterus brachyotis ankle, demonstrating

501 separation between the calcar and the tendon of the gastrocnemius muscle. (a) - (c) are

502 dissection photos of an iodine-stained specimen. (b) pin demonstrates the separation between the

503 calcar and the tendon. (c) shows the insertion of the calcar on the calcaneal tuberosity after the

504 tendon has been dissected out. (d) is a slice of the diceCT scan demonstrating the separation

505 between the calcar and the tendon and their two distinct insertions on the calcaneus. $\mathrm{Ca}=$ calcar,

$506 \mathrm{Cs}=$ calcaneus, $\mathrm{tm}=$ tendon of the gastrocnemius muscle.
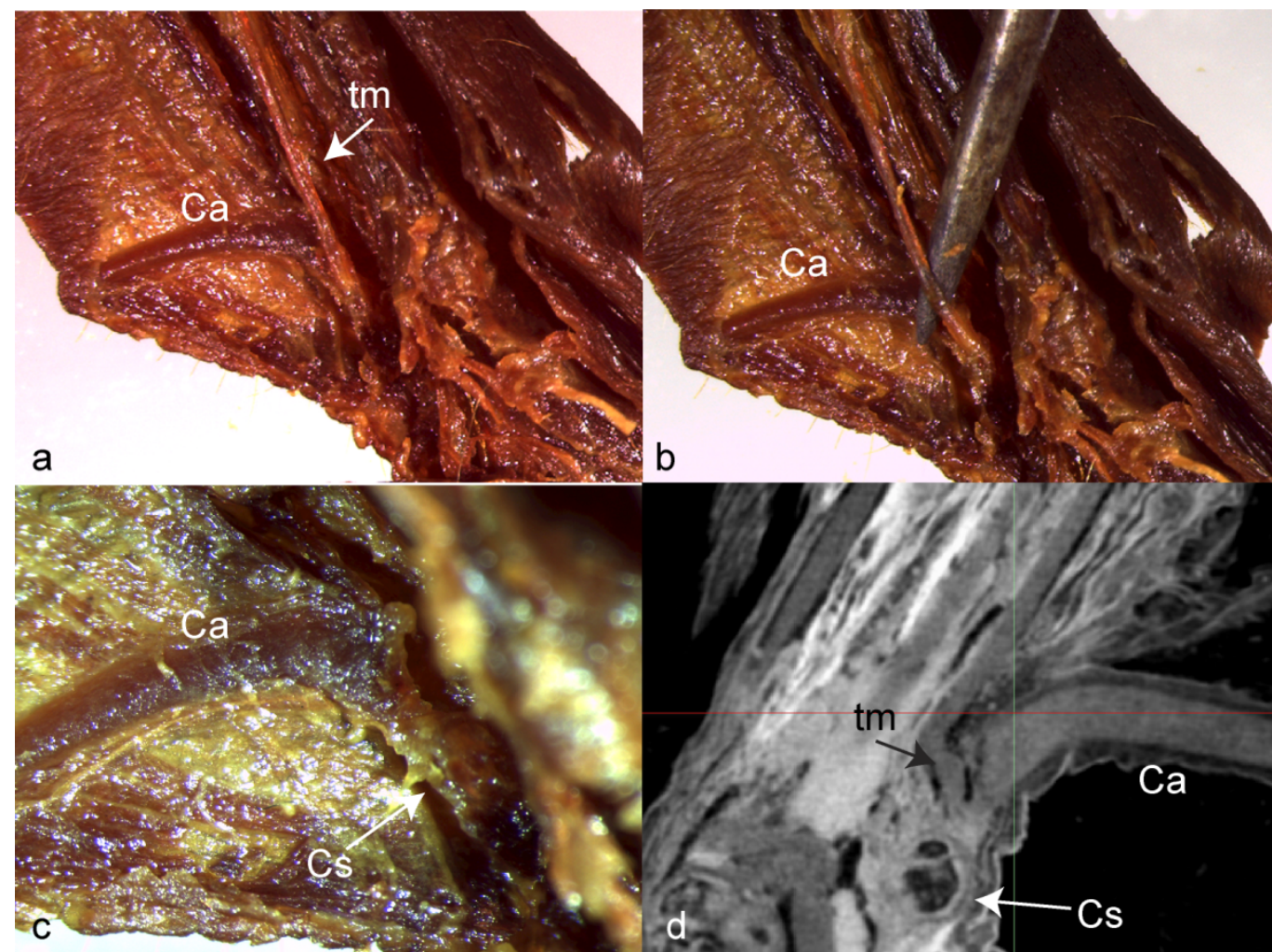

b 


\section{REFERENCES}

514 Adams, R.A. and Thibault, K.M. 1999. Growth, development, and histology of the calcar in the 515 little brown bat, Myotis lucifugus (Vespertilionidae). Acta chiropterologica 1:215-221.

516 Altenbach, J.S.1989. Prey capture by the fishing bats Noctilio leporinus and Myotis vivesi.

517 Journal of Mammalogy 70:421-424.

518 Amador, L.I., Giannini, N.P., Simmons, N.B. and Abdala, V., 2018. Morphology and evolution 519 of sesamoid elements in bats (Mammalia: Chiroptera). American Museum Novitates, 3905:1$520 \quad 40$.

521 Bennett, S.C., 2007. Articulation and function of the pteroid bone of pterosaurs. Journal of 522 Vertebrate Paleontology, 27:881-891.

523 Blomberg, S.P., Garland Jr., T., and Ives, A.R. 2003. Testing for phylogenetic signal in 524 comparative data: Behavioral traits are more labile. Evolution 57:717-745.

525 Butler M.A. and King, A.A. 2004. Phylogenetic comparative analysis: a modeling approach for 526 adaptive evolution. American Naturalist 164:683-695.

527 Carter, D.R., and Beaupré, G S. 2007. Skeletal function and form: mechanobiology of skeletal 528 development, aging, and regeneration. Cambridge Univ. Press.

529 Cheney, J.A. et al. 2014. Hindlimb motion during steady flight of the lesser dog-faced fruit bat, $530 \quad$ Cynopterus brachyotis. Plos one 9, e98093.

531 Coster, P., Beard, K.C., Salem, M.J., Chaimanee, Y. and Jaeger, J.J., 2015. New fossils from the 532 Paleogene of central Libya illuminate the evolutionary history of endemic African 533 anomaluroid rodents. Frontiers in Earth Science, 3:56.

534 Currey, J.D. 2002. Bones: structure and mechanics. Princeton Univ. Press. 
536 Czech, N.U., Klauer, G., Dehnhardt, G., and Siemers, B.M. 2008. Fringe for foraging? Histology

537 of the bristle-like hairs on the tail membrane of the gleaning bat, Myotis nattereri. Acta

538 chiropterologica 10:303-311.

539 Eyal, S., Blitz, E., Shwartz, Y., Akiyama, H., Schweitzer, R. and Zelzer, E., 2015. On the

540 development of the patella. Development, 142:1831-1839.

541 Eyal, S., Rubin, S., Krief, S., Levin, L. and Zelzer, E., 2018. On the Development of Sesamoid

542 Bones. bioRxiv, doi: https://doi.org/10.1101/316901.

543 Felsenstein J. 1973. Maximum likelihood estimation of evolutionary trees from continuous

$544 \quad$ characters. American Journal of Human Genetics 25:471-492.

545 Felsenstein, J. 1985. Phylogenies and the comparative method. American Naturalist 125:1-15.

546 Fenton, M.B. and Bogdanowicz, W. 2002. Relationships between external morphology and

547 foraging behavior: bats in the genus Myotis. Canadian Journal of Zoology, 80, 1004-1013.

548 Fenton, M.B. and Simmons, N.B. 2015. Bats: A World of Science and Mystery. Univ. of Chicago

$549 \quad$ Press.

550 Fish, F. E., Blood, B. R., and Clark, B. D. 1991. Hydrodynamics of the feet of fish-catching bats:

551 Influence of the water surface on drag and morphological design. Journal of Experimental

$552 \quad$ Zoology 258:164-173.

553 Gignac, P.M., et al. 2006. Diffusible iodine-based contrast-enhanced computed tomography

554 (diceCT): an emerging tool for rapid, high-resolution, 3-D imaging of metazoan soft tissues.

555 Journal of anatomy 228:889-909.

556 Glass, P.J. and Gannon, W.L. 1994. Description of M. uropataginalis (a new muscles), with

557 additional comments from a microscopy study of the uropatagium of the fringed myotis

558 (Myotis thysanodes). Camadian Journal of Zoology 72:1752-1754. 
Hall, B.K. 2015. Bones and Cartilage. Academic Press.

Halliday, T.J.D., Upchurch, P., Goswami, A. 2017. Resolving the relationships of Paleocene

562 Hand, S.J., Sigé, B., Archer, M., Gunnell, G.F., and Simmons, N.B. 2015. A New Early Eocene (Ypresian) Bat from Pourcy, Paris Basin, France, with Comments on Patterns of Diversity in

Hansen, T.F. 1997. Stabilizing selection and the comparative analysis of adaptation. Evolution, 51:1341-1351.

\section{7}

Harmon, L.J., Schulte, J.A., Losos, J.B., and Larson, A. 2003. Tempo and mode of evolutionary radiation in igunaian lizards. Science 301:961-964.

Harmon, L.J., Weir, J.T., Brock, C.D., Glor, R.E., and Challenger, W. 2007. GEIGER: investigating evolutionary radiations. Bioinformatics 24:129-131.

Harmon L.J. et al. 2010. Early bursts of body size and shape evolution are rare in comparative data. Evolution 64:2385-2396.

Hibbeler, R.C. 2007. Mechanics of Materials. Prentice Hall.

Humason, G.L. 1962. Animal Tissue Techniques. W.H. Freeman and Co.

Erwin, D.H., 2015. Novelty and innovation in the history of life. Current Biology, 25:R930-

$$
\text { R940. }
$$

Jackson, S.M., 2012. Gliding mammals of the world. CSIRO Publishing.

Johnson-Murray, J. L. (1987). The comparative myology of the gliding membranes of Acrobates,

579 Petauroides and Petaurus contrasted with the cutaneous myology of Hemibelideus and

580 Pseudocheirus (Marsupialia, Phalangeridae) and with selected gliding rodentia (Sciuridae and

581 Anamoluridae). Australian Journal of Zoology, 35:101-113. 
582 Kawashima, T., Thorington Jr, R.W., Bohaska, P.W. and Sato, F., 2017. Evolutionary

583 Transformation of the Palmaris Longus Muscle in Flying Squirrels (Pteromyini: Sciuridae):

584 An Anatomical Consideration of the Origin of the Uniquely Specialized Styliform

585 Cartilage. The Anatomical Record, 300:340-352.

586 Kobayashi, M. 2017. Homology of the muscles within the uropatagium membrane in

587 Leschenault's rousette (Rousettus leschenaultii). Mammalian Biology-Zeitschrift für

588 Säugetierkunde, 86:102-106.

589 Koyabu, D., and Son, N. T. 2014. Patterns of postcranial ossification and sequence heterochrony

590 in bats: Life histories and developmental trade-offs. Journal of Experimental Zoology Part B:

$591 \quad$ Molecular and Developmental Evolution 322:607-618.

592 Kunz, T.H. and Fenton, M.B., eds. 2005. Bat Ecology. Univ. of Chicago Press.

593 López-Fernández, H., Arbour, J.H., Winemiller, K.O. and Honeycutt, R.L., 2013. Testing for

594 ancient adaptive radiations in Neotropical cichlid fishes. Evolution, 67:1321-1337.

595 Meng, Q.J., Grossnickle, D.M., Liu, D., Zhang, Y.G., Neander, A.I., Ji, Q. and Luo, Z.X., 2017.

596 New gliding mammaliaforms from the Jurassic. Nature, 548:291.

597 Müller, G.B. and Wagner, G.P. 1991. Novelty in evolution: restructuring the concept. Annual

598 review of ecology and systematics 22:229-256 (1991).

599 Pennell, M.W., et al. 2014. geiger v2.0: an expanded suite of methods for fitting macroevolution

600 models to phylogenetic trees. Bioinformatics 30:2216-2218.

601 R Core Team. 2017. R: A language and environment for statistical computing.

602 Revell, L. J. 2009. Size-correction and principal components for interspecific comparative

$603 \quad$ studies. Evolution, 63:3258-3268. 
604 Revell, L. J. 2010. Phylogenetic signal and linear regression on species data. Methods in Ecology

605 and Evolution, 1:319-329.

Revell, L.J. 2012. phytools: An R package for phylogenetic comparative biology (and other things). Methods in Ecology and Evolution 3:217-223.

Revell, L.J. 2013. Two new graphical methods for mapping trait evolution on phylogenies. Methods in Ecology and Evolution 4:754-759.

Reyes-Amaya, N., Jerez, A., and Flores, D. 2017. Morphology and Postnatal Development of

611 Lower Hindlimbs in Desmodus rotundus (Chiroptera: Phyllostomidae): A Comparative Study. The Anatomical Record 300:2150-2165.

613 Sarin, V.K., Erickson, G.M., Giori, N.J., Bergman, A.G. and Carter, D.R., 1999. Coincident 614 development of sesamoid bones and clues to their evolution. The Anatomical Record. 257:174-180.

Schutt, W.A. and Simmons, N.B., 1998. Morphology and homology of the chiropteran calcar, with comments on the phylogenetic relationships of Archaeopteropus. Journal of Mammalian Evolution, 5:1-32.

Shi, J.J. and Rabosky, D.L. 2015. Speciation dynamics during the global radiation of extant bats.

$$
\text { Evolution 69:1528-1545. }
$$

621 Shubin, N., Tabin, C., and Carroll, S. 2009. Deep homology and the origins of evolutionary novelty. Nature 457:818-823.

623 Simmons, N.B. Order Chiroptera. 2005. Mammal Species of the World: A Taxonomic and Geographic Reference. 312-529. Johns Hopkins Univ. Press.

625 Simmons, N.B., Seymour, K.L., Habersetzer, J., and Gunnell, G.F. 2008. Primitive Early Eocene 626 bat from Wyoming and the evolution of flight and echolocation. Nature 451:818-821. 
627 Simmons, N.B. and Geisler, J.H., 1998. Phylogenetic relationships of Icaronycteris,

628 Archaeonycteris, Hassianycteris, and Palaeochiropteryx to extant bat lineages, with

629 comments on the evolution of echolocation and foraging strategies in Microchiroptera.

$630 \quad$ Bulletin of the AMNH, 235.

631 Simmons, N.B. and Quinn, T.H. 1994. Evolution of the digital tendon locking mechanism in bats

632 and dermopterans: a phylogenetic perspective. Journal of Mammalian Evolution 2:231-254.

633 Slater, G.J., Price, S.A., Santini, F., and Alfaro, M.A. 2010. Diversity vs disparity and the

634 evolution of modern cetaceans. Proceedings of the Royal Society B 277:3097-3104.

635 Slater, G.J. and Pennell, M.W., 2013. Robust regression and posterior predictive simulation

636 increase power to detect early bursts of trait evolution. Systematic Biology, 63:293-308.

637 Slater, G.J. and Friscia, A.R., 2018. Hierarchy, Morphology, and Adaptive Radiation: a Test of

638 Osborn's Law in the Carnivora. bioRxiv, doi: https://doi.org/10.1101/285700.

639 Smith, T., Habersetzer, J., Simmons, N.B., and Gunnell, G.F. 2012. Systematics and

640 paleobiogeography of early bats. Evolutionary History of Bats: Fossils, Molecules and

641 Morphology. 23-66. Cambridge, Univ. Press.

642 Stanchak, K.E. and Santana, S.E. 2018. Assessment of the hindlimb membrane musculature of

643 bats: Implications for active control of the calcar. The Anatomical Record 301, 441-448.

644 Storch, G., Sigé, B. and Habersetzer, J., 2002. Tachypteron franzeni n. gen., n. sp., earliest

645 emballonurid bat from the Middle Eocene of Messel (Mammalia,

646 Chiroptera). Paläontologische Zeitschrift, 76:189-199.

647 Teeling, E.C., et al. 2005. A molecular phylogeny for bats illuminates biogeography and the

648 fossil record. Science 307:580-584.

649 Vaughan, T.A., 1970. The skeletal system. Biology of bats v1, 98-139. Academic Press, NY. 
650 Witton, M.P., 2013. Pterosaurs: natural history, evolution, anatomy. Princeton University Press.

651 Xu, X., Zheng, X., Sullivan, C., Wang, X., Xing, L., Wang, Y., Zhang, X., O’Connor, J.K.,

652 Zhang, F. and Pan, Y., 2015. A bizarre Jurassic maniraptoran theropod with preserved

653 evidence of membranous wings. Nature, 521:70. 